\title{
Institutional Supervision: Mediation, Mentorship and Facilitation for Distance Learning Master's Degrees
}

\author{
Carolina A. Magaldi, Carla S. Machado, Juliana A. Magaldi, and Marcos T. Sanábio
}

\begin{abstract}
This study aims to discuss the system of institutional supervision adopted by the Professional Master's Degree in Educational Management, offered by the Federal University of Juiz de Fora (UFJF) in Brazil, as a means of exploring its contribution to the scope of teaching, tutoring and mentoring in distance learning graduate programs.
\end{abstract}

Index Terms-Professional master's degree, supervision, distance learning, mentoring.

\section{INTRODUCTION}

The system of institutional supervision, developed by the Professional Master's Degree in Educational Management, offered by the Center for Public Policies and Assessment in Education (CAEd), part of the Federal University of Juiz de Fora (UFJF) in Brazil, represents a possibility for expanding the scope of teaching, facilitating and mentoring among those responsible for providing supervision and guidance to the writing of a dissertation.

In order to explore such pedagogical choice, we will provide an outlook of the graduate program in question, a description of its supervision system, as well as a discussion regarding the reinterpretation of traditional teaching roles in distance learning.

\section{The Program}

The Professional Master's Degree in Educational Management, offered by the Federal University of Juiz de Fora was created in 2009. Every year about 120 students are selected from an average of 15 different Brazilian states, as well as from two other Portuguese speaking countries: Mozambique and Angola.

Its twenty three faculty members are allocated at the departments of Education, Business Management and Social Sciences. Apart from its teaching staff, the master's degree also has in its pedagogical ranks: online tutors for every discipline, case studies experts, academic support agents and assistant supervisors, composing its institutional supervision teams.

The first class began their activities in October 2010. The teaching method is semi-presential, with activities taking place online via Moodle Platform during the academic terms,

Manuscript received May 23, 2013; revised September 10, 2013 Institutional supervision as a combination of mediation, mentorship and facilitation for distance learning master's degrees

Carolina A. Magaldi is with CAEd/UFJF and the Brazilian Open University (e-mail: cmagaldi@caed.ufjf.br, cmagaldo@caed.ufjf.br, mtanure.sanabio@ufjf.edu.br ).

Carla S. Machado, Juliana A. Magaldi, and Marcos T. Sanábio are with CAEd/UFJF (e-mail: cmagaldo@ caed.ufjf.br). and presential periods in January and July, coinciding with school breaks in Brazil. The target audience of the master's program is school managers - principals, education secretariat professionals, education experts from public universities and from the Ministry for Education.

Throughout of the two years of disciplines, the students acquire the theoretical background necessary to conducting their studies, encompassing topics such as leadership, accountability, decision making, external assessment and curriculum, among others.

In addition to the disciplines, during the second and final year of the program the candidates write a dissertation as a partial requirement for obtaining the master's degree.

\section{THE DISSERTATION}

During the first year of the program, the candidates choose a topic for their case study and write a dissertation project, usually focusing on their own professional environment. The program focuses on two types of case studies: analyzing a situation and discussing a public policy. The latter can be further divided into discussing the design of a policy or debating its implementation process.

Once the case has been successfully developed, which generally coincides with the end of the first year of the program, the students may begin the second stage of writing, commencing their dissertations.

The dissertation itself is divided into a first chapter dedicated to their case study; a second part in which such case is analyzed via theoretical discussion and fieldwork; and a final chapter which brings an intervention proposed by the candidate, aiming to address the issues uncovered by their research, hopefully providing a positive impact for the development of the Brazilian public education system as a whole.

\section{The InSTITUTIONAL SUPERVISION TEAMS}

Given the semi-presential nature of the program, its interdisciplinary characteristics and the large number of students in each class, the program decided to adopt a system of institutional supervision for their dissertations.

In such design, rather than being supervised by an individual, each candidate is paired with a supervision team, headed by a tenured professor, who handles a maximum of eight dissertations, and is responsible for the more fundamental matters of the writing process, such as choosing a theoretical approach and overseeing methodological choices. The other two members of the team are an academic support agent, who usually oversees three groups of eight students each, and is responsible for the 
maintenance of the structure of the dissertation in three chapters (case description, analysis and proposal) and an assistant supervisor, also responsible for eight students, who interacts more directly with the candidates via online platform, guaranteeing the dialogue between the members of the supervision team and suggesting ways to make sure that the recommendations of the two other members of the unit come to fruition in the texts.

Academic support agents and assistant supervisors are part of a department known as the Dissertation Nucleus, which has a coordination of its own, under Professor Juliana Magaldi. The nucleus keeps a schedule of weekly meetings, alternating internal matters and external training seminars.

Focusing more specifically on the process of supervision, the interaction between master's degree students and the supervision team takes place, during the academic terms, via Moodle Platform, with new tasks leading to improved version of their dissertations being posted every two weeks. The first round of feedback is conducted by the assistant supervisor, which is then forwarded to the academic support agent and finally to the tenured professor. Finally, it returns to the assistant supervisor, who contacts the student with the new supervision guidelines.

The system of institutional supervision was designed to answer the pedagogical demands of the high scale of dissertations produced in the master's degree in question, as well as the characteristics of the student body, composed mainly of high skilled professionals who had distanced themselves from academic discussion, We may argue that the system covers all the forms of teaching presence discussed by Stavredes \& Gerder (2013) [1]: social presence is achieved among the students by organizing groups of candidates with similar goals in their dissertations, as well as by keeping a close and constant contact between such students and the members of their supervision teams; cognitive presence is reached through the feedback strategy, in which every each commented version is accompanied by a series of questions and remarks designed to increase the quality and focus of the research being conducted; and teaching presence is made visible through the seminars offered by the dissertation nucleus during the presential periods, and their continued discussion through the virtual learning environment.

The process of supervision is always organized in a circular manner. From the students' point of view each submission is followed by the institutional supervision feedback, which is then posted to the candidate, thus commencing a new bi-weekly cycle.

From the supervision team's perspective, the work is also conducted in circularly. When a student submits a new version of their dissertations, their first contact is always with the assistant supervisor. They will then have two to three days to highlight the main achievements of that stage in production, as well as the possible new challenges to be addressed in the next posting. Such work is normally conducted using revision tools of Word for Windows.

The commented dissertation is then forwarded to the academic support agent, who also have between two and three days to observe the pertinence of the text regarding the program's research lines and the standards of each dissertation, adding their own observations to the text.
Normally, by the end of the week the commented text is posted to the candidate.

A third reading, by the tenured professor, is conducted at least twice during the semester. In such occasions, the text is sent back to the assistant supervisor, who will then organize the new goals for the next posting and address each student individually.

During the first text submissions, the feedbacks are posted simultaneously to all students. As the year progresses, students show different work rhythms and reveal their difficulties in certain areas of academic writing, which leads the teams to manage their efforts in order to contribute to each candidate's individual research needs. However, the overall standards of one week to nine days between posting and feedback remain constant.

Following the feedback, each assistant supervisor may suggest different means of establishing dialogue with the candidates, ranging from video conferencing, instant messages and face-to-face meetings whenever possible. Such decisions are discussed with the entire team and are based on the challenges being faced by the student and on the need to provide the candidate with the necessary tools to overcome them.

During the presential period, the students have individual meetings with their supervision team, as well as collective sessions with the eight members of their group, in order to exchange experiences and discuss the common ground that lead to their dissertations.

As argued by Zane Berge and Mauri Collins (1995) [2], although computer based technology has changed the structure of educational systems and made it possible to diversify the methods and principles of distance learning, old technologies are augmented, not totally replaced, as exemplified by the lasting popularity of lecture classes. In our case, such characteristic may the noted by the use of new supervision tools (video conferencing and virtual learning environments), while maintaining an emphasis on individual feedbacks and face-to-face meetings among the members of the supervision teams. The existence of a virtual library and of a physical one also should be noted, even when it means allowing for semester-long book loans for the master's degree students.

Berge and Collins also discuss the focus on the student as part of a shift between the concepts of distance education and distance learning, arguing that transferring knowledge has lesser ties with what is done by the teacher than with what learners are encouraged to do themselves [1].

The encouragement mentioned by the authors needs to be nurtured by the entire system of teachers, tutors and mentors or, in our case, by all the three members of the institutional supervision team.

\section{Tutoring, Teaching, Mentoring}

Erping Zhu (1996), in his study regarding mentoring in distance learning, applied a theoretical framework anchored in Vigotsky's theories to explore meaning negotiations and the construction of knowledge between students, teachers, tutors and mentors. He focused on the Russian theorist's concept of zone of proximal learning to comprehend the role 
of virtual learning environments as zones in which both student and teacher may express their opinions and reflect upon their learning, creating interactions which maximize the student's cognitive growth and development [3]

In distance learning, given the geographical and chronological gap between students and teacher, methodological approaches must take the students' own independence as a fundamental part of building the zone of proximal learning.

Originally, the teaching roles in distance learning contexts were divided between a teacher, responsible of organizing the syllabus and for most the pedagogical decisions, and a tutor, in charge of online interactions and also working as a teaching assistant.

More recently, the role of mentorship has become more prominent in online learning environments, increasing the value of dialogue and collective construction of knowledge. This recent shift is marked by a more interactive concept of learning, in which mentors forsake lecturing and choose to promote discussion, challenge students, and offer guidance [4].

Given that all the members of the supervision team aim to catalyze the production of a successful dissertation, they must do so through dialogue, providing not only corrections of the path chosen by the students, but also providing them with the right questions to foment their scientific curiosity when looking for ways to analyze their case studies and propose interventions.

Every member of the team also commits to pedagogical mediation by contributing to the application of the knowledge gathered in the disciplines into the dissertation [5]. Moreover, the role of the assistant supervisor in helping the candidates organize their study and writing routines brings the supervision team once more to the scope of mentorship, a factor intrinsically connected to academic success [6].

Several challenges have emerged from this unique structure of supervision, such as having different degrees of commitment among the team members, tense negotiations regarding methodological choices or theoretical ones among the team members, as well as students who tend to identify more closely with a single member of the team.

However, none of those hurdles have been able to eclipse the main point of agreement regarding institutional supervision, as members of all the institutional supervision teams agree that the candidates from the Professional Master's Degree in Educational Management are far more motivated than those allocated in any other graduate program they have worked with.

Tapia and Fita (1999) [7], organize the possible reasons for education motivation into four groups:

a) Intrinsic motivation, a type of drive that comes from the subject itself, taking place when a student feels connected to a subject.

In being a professional master's degree, the students have already chosen the field of education as their professional path, being also encouraged to select a case study directly related to their work environment, possibly providing answers to long-withstanding issues. It is up to the supervision team to make sure that the expertise that they have gathered through their work finds its way into the text.

b) Self-esteem related motivation, which is always provided by the supervision team in the form of notes and letters written in each commented version of their text, to point out the advances accomplished in each new posting. The points which need to be rewritten or deepened are also presented as new goals for their next posting.

c) Socially-related motivation, which is related to being acknowledged by their teachers and peers.

By organizing the students in groups based on their chosen case studies, the students are able to develop a sense of camaraderie on the course of writing a dissertation, turning a normally solitary activity into a collective one by keeping virtual discussion chambers in which the master's degree candidates themselves may recommend books and suggest methodological approaches to each other.

d) Reward-related motivation, a type of drive of questionable efficacy, given that it provides a form of validation external to the study itself.

In the case of the institutional supervision, it takes place by reminding the students of the joy of defending their work before a panel of distinguished professors, and of sharing that moment with classmates, friends and family.

\section{CONCLUSION}

The institutional supervision system adopted by the Professional Master's Degree in Educational Management, offered the Center for Public Policies and Assessment in Education (CAEd), part of the Federal University of Juiz de Fora (UFJF) in Brazil has become an intrinsic part of the program's identity, contributing to the writing of quality dissertations and to bringing greater focus to the topic of mentoring in computer-mediated graduate programs.

While it remains under constant reassessment by its own teams, by the responsible educational organs, as well as by the professors who come to the defense panels, it has managed to prove itself not only a valid form of supervision, but also a possible alternative to improve motivation and dialogue in distance learning master's degrees.

\section{REFERENCES}

[1] T. Stavredes and T. Herder, "Student persistence - and teaching strategies to support it," in M. Moore ed., Handbook of Distance Education, New York and London: Routledge, 2013, pp. 30.

[2] Z. Berge and M. Collins, Computer-mediated communication and the online classroom in higher education, New York: Hampton Press, 1995.

[3] Z. Erping, "Meaning Negotiation, Knowledge Construction, and MENTORING in a Distance Learning Course," in Proc.Selected Research and Development Presentations at the 1996 National Convention of the Association for Educational Communications and Technology, 1996, pp. 822-844.

[4] M. Srivastava, "Mentoring in Open and Distance Learning: Its application at Indira Gandhi National Open University, India," $2^{\text {nd }}$ Pan-Commonwealth Forum on Open Learning, 2002.

[5] F. Cruz, T. Lima, and M. Padilha, "A visão de alunos sobre o conceito de Educação a Distância e a possibilidade de autonomia e interatividade no ambiente virtual de aprendizagem (AVA)," III Congresso Internacional ABCiber, 2009.

[6] S. Janasz, E. Ensher, and C. HEUN, "Virtual relationships and real benefits: using e-mentoring to connect business students with practicing managers," Mentoring and Tutoring: Partnership in Learning, New York: Routledge, pp. 394-411, 2008.

[7] J. Tapia and E. Fita, A motivação em sala de aula - O que é, como se faz, São Paulo: Edições Loyola, 1999. 


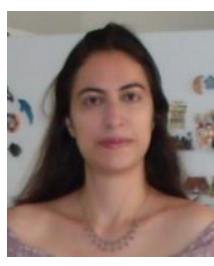

Carolina Alves Magaldi was born in Juiz de Fora, Brazil, on the $17^{\text {th }}$ of November, 1979. She has three bachelor degrees in Portuguese (2001), English (2002) and Italian (2005) languages and respective literatures. She has a Master's degree in Liberal Arts (2006) and a Doctor's degree (2013) in the field of comparative literature. All of those degrees are from the Federal University of Juiz de Fora (UFJF).

She has taught at Estácio de Sá College, and at the Federal University of Juiz de Fora as a temporary lecturer. She has been a part of the Institutional Supervision Team at CAEd/ UFJF since February. 2012 and is currently a Visiting Professor at the Brazilian Open University (UAB). Among her recent publications there is an entry at the Brazilian Dictionary of Educational Terms, an article regarding school management, entitled The other side of the coin, and an article regarding hospital education in Brazil, to be presented at the XV World Congress of Comparative Education.

Her research spans the fields of Education, Foreign language teaching, Literature and Translation.

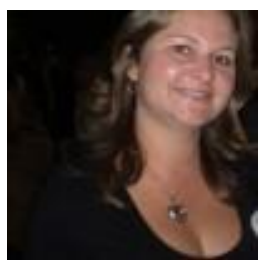

Carla Silva Machado was born in Juiz de Fora, Brazil, on the $18^{\text {th }}$ of October, 1976. She has a bachelor degree in Liberal Arts from the Federal University of Viçosa (UFV), and a Master's degree in Education from the Federal University of Juiz de Fora (UFJF).

She has taught at Unipac College, and has been a part of the Institutional Supervision Team at CAEd/ UFJF since 2011. Among her recent publications there is an entry at the Brazilian Dictionary of Educational Terms, an article regarding school management, entitled The other side of the coin, and an article regarding hospital education in Brazil, to be presented at the XV World Congress of Comparative Education.

Her research spans the fields of Education, and Children's Literature.

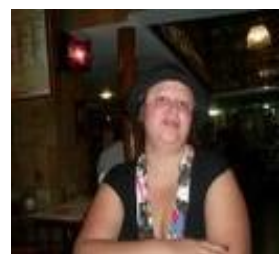

Juliana Alves Magaldi was born in Juiz de Fora, Brazil, on the $22^{\text {th }}$ of April, 1976. She has a bachelor degree in social sciences from the Federal University of Juiz de Fora (UFJF), a Master's degree in Anthropology from the Fluminense Federal University (UFF, 2002) and a Doctor's degree in Anthropology of Religion from the Federal University of Juiz de For a (UFJF).

She has taught at Unipac College, and has been a part of the Institutional Supervision Team at CAEd/ UFJF since 2011. Among her recent publications there is an entry at the Brazilian Dictionary of Educational Terms.

Her research spans the fields of Education, Religion and Consumism.

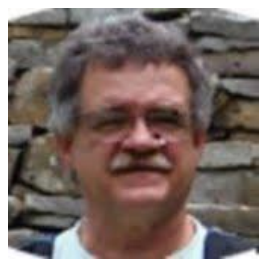

Marcos Tenure Sanábio was born in Juiz de Fora, Brazil. He has a bachelor degree in accounting and administration from the Machado Sobrinho College, a Master's degree in Public Management from Getúlio Vargas Foundation (FGV) and a doctor's degree in Management from the Federal University of Lavras (UFLA).

He has been a tenured professor at the Federal University of Juiz de Fora Since 1990 and has been a part of the Institutional Supervision Team at CAEd/ UFJF since 2011. Among his recent publications there is an article regarding school management, entitled The other side of the coin, and an article regarding hospital education in Brazil, to be presented at the XV World Congress of Comparative Education.

His research spans the fields of Management, Public Administration and School Administration and Higher Education. 